\title{
Relationship between Perceived Parenting styles and Depressive Symptoms among Selected University Students
}

\author{
Manal M. Abdel Hamied ${ }^{1}$, Maaly I. El Malky², Lamia H. Eita ${ }^{3}$, Faten H. \\ Alam ${ }^{4}$ \\ ${ }^{12}$ Assistant professor of psychiatric Nursing, Faculty of Nursing, Menoufia University. \\ ${ }^{34}$ lecturer of psychiatric Nursing, Faculty of Nursing, Menoufia University.
}

\begin{abstract}
Parenting styles have crucial impacts on the psychological development of the adolescents and their future, such as health, mental well-being, academic achievement, selfesteem, and risk-taking behavior. The purpose of this study was to assess the relationship between perceived parenting style and depressive symptoms among college students. The Design of this study was a descriptive co-relational design. This study was conducted at two faculties in Menoufia University (faculty of art and faculty of nursing). A systematic random sample consisted of 527students who were selected from the above mentioned setting. Two instruments were used for data gathering. Parental Authority Questionnaire and Patient Health Questionnaire (PHQ-9) depression scale. The results of this study indicated that the most common parenting styles used among the studied sample was moderate authoritative style. Also more than half of the students had mild depressive symptoms. Conclusion: this study concluded that there was a positive correlation between authoritarian parenting style and depressive symptoms. Therefore, it is recommended that, an educational program should be given for the parents' of adolescents to increase their awareness about their adolescences' needs, problems and how to satisfy their needs and adapt with their problems.
\end{abstract}

Keywords: Perceived Parenting styles, Depressive Symptoms.

\section{Introduction:}

Adolescence is often conceptualized as a crucial period for youth in preparation for adulthood. Multiple systems are involved in this preparation and orientation, resulting in a complex process that influences adolescent's thinking and planning about adulthood and future goals (Iovu, 2014). Parenting styles are significant factors in human development studies and have been known as important causes of sociability in adolescents. Parenting styles include methods that parents apply for treating their children, and have profound impact on adolescent's growth, their character, personality and behavioral traits (Kumari and Khanna, 2016).

Parenting style has been defined as the manner in which parents treat, communicate with, discipline, monitor, and support their children (Elstad and Stefansen, 2014). Perceived parenting styles defined as an opinion of adolescences or children about styles of parental behaviors a positive relationship with primary caregivers is important for developing healthy behaviors and skills that lead to successful functioning as a college student. Relationships with parents and other attachment figures have long been identified as playing an important role in psychosocial development and functioning, the effects of which persist far into adulthood (Clark, 2015).

Adolescence is considered to be a period of more often manifestation of depressive mood, although depression is found more often in children before puberties, especially in girls. The risk for depression increases in adolescence (Lasic et al., 2014).

Depression is defined according to the WHO as a common mental disorder, characterized by sadness, loss of interest or pleasure, feelings of guilt or low self- 


\section{Relationship between Perceived Parenting styles and Depressive Symptoms among Selected University Students}

worth, disturbed sleep or appetite, feelings of tiredness, and poor concentration (Gogoi, 2016). Parenting styles in adolescence may result in levels of depressive symptoms that interfere with educational achievement. Depression has consistently been identified as a significant risk factor for suicide attempts in university students (Yu et al., 2015)The nurse should provide a comprehensive strategy that includes awareness and educational activities that highlight and encourage reduction of suicide risk factors; early identification of at-risk students; counseling services for students at varying levels of risk; and clear policies and procedures for handling student risk behaviors, supporting at-risk students. (American Foundation for Suicide Prevention, 2016).

\section{PURPOSE}

The present study was carried out to assess the relationship between perceived parenting styles, depressive symptoms among college students.

\section{RESEARCH QUESTIONS}

1) What are the perceived parenting styles among college students?

2) Is there a relationship between the perceived parenting styles and depressive symptoms?

\section{Ooperational definition:}

In the present study perceived parenting styles are operationally defined as opinion of adolescences about parenting behaviors of parents according to mean score of parental Authority Questionnaire developed by Buri, 1991.

In the present study, depression is operationally defined as the existence of complaints such as loss of interest, loss of appetite and poor concentration that were assessed using patient health (PHQ-9) depression scale developed by Robert et al., 2005.
1) Research Design: A descriptive corelational design was used.

2) Research Setting: This study was conducted in faculty of art and faculty of nursing in Menoufia University.

3) Sampling: A convenience sample of 527 adolescents was selected from the previously mentioned settings .Sample size has been calculated using the following equation: $\mathrm{n}=(\mathrm{z} 2 \times \mathrm{p} \times$ q)/D2 at power $80 \%$ and CI $95 \%$.A simple random sample was used to assign the students into study.

\section{Inclusion criteria:}

1) All students should range from 18-22 years.

2) All students should be in first and second year.

\section{Exclusion criteria:}

Students with Any chronic physical illness, history of psychiatric diseases, history of substance abuse and history of neurological problems. Such illnesses could cause depression.

\section{Instruments:}

Two instruments were used in this study:

Instrument (1): parental Authority Questionnaire. These instruments included two parts.

Part one: Social characteristics of the sample .It included age, sex, place of residence and information about family such as father and mother's occupation, educational level.

Part two: parental Authority likert scale, It was developed by Buri, 1991. It was used to assess adolescents' perception of parenting styles (authoritarian, authoritative, and permissive). It consisted of 30-item.Ten items were equally used to assess each type of parenting style.

Scoring system for each item

\section{METHODS}


Relationship between Perceived Parenting styles and Depressive Symptoms among Selected University Students

\begin{tabular}{|c|l|}
\hline Score & \multicolumn{1}{|c|}{ Scoring items } \\
\hline 5 & \multicolumn{1}{|c|}{ Strongly agree } \\
\hline 4 & Agree \\
\hline 3 & Neither agree nor disagree \\
\hline 2 & Disagree \\
\hline 1 & Strongly disagree \\
\hline
\end{tabular}

Total scoring system for each style (authoritarian, authoritative, and permissive)

\begin{tabular}{|l|c|}
\hline None & $<30$ \\
\hline Mild & $30-36$ \\
\hline Moderate & $37-43$ \\
\hline High & $44-50$ \\
\hline
\end{tabular}

Instrument (2): Patient Health Questionnaire (PHQ-9) depression scale. It was developed by Robert et al., (2005). It was used to assess depressive symptoms .It was translated into Arabic by the researcher and consisted of nine items.

Scoring system for each item

\begin{tabular}{|c|l|}
\hline Score & Scoring items \\
\hline 3 & nearly every day \\
\hline 2 & more than half the days \\
\hline 1 & several days \\
\hline 0 & not at all \\
\hline
\end{tabular}

2) All the instruments were tested for its content validity by 5 experts in the field of psychiatric nursing to ascertain the relevance and completeness of the instruments.

3) Test-retest was used to assess the reliability of instrument one $(\mathrm{r}=0.89)$ and two $(\mathrm{r}=0.84)$

4) A Pilot study was carried out on $10 \%$ of total sample (53students) after the instruments were developed and before starting data collection to test the applicability, clarity and the feasibility of the study tools and to estimate the needed time to fill the tool.

5) For ethical consideration an oral acceptance was obtained from each student after explaining the purpose of the study and methods of data collection .They were assured about the confidentiality of their data .They
Total scoring system for depression scale

\begin{tabular}{|l|c|}
\hline Mild & $5-9$ \\
\hline moderate & $10-14$ \\
\hline moderately severe & $15-19$ \\
\hline severe & $20-27$ \\
\hline
\end{tabular}

\section{Procedure:}

1) Before data collection an official letter explaining the purpose and methods of data collection was submitted from the dean of faculty of nursing to the dean of faculty of art .two other official letters were submitted from the dean of faculty of nursing to the heads of departments of the first and second year in faculty of art and faculty of nursing .Data collection was done through distributed questionnaires between students after explaining the purpose, methods of data collection and how to fill the utilized sheets. .Each students spent 2030 minutes to fill the two instruments. Data was collected from two to three dayslweek. Data collection lasted between march 2016 to may 2016.

were told that participation was voluntary and they had the right to refuse to participate at any time.

\section{DATA ANALYSIS:-}

The collected data were organized, tabulated and statistically analyzed using SPSS software (Statistical Package for the Social Sciences, version 20, SPSS Inc. Chicago, IL, USA). Descriptive statistics: quantitative data were presented in the form of mean $(\overline{\mathrm{X}})$, standard deviation (SD) and qualitative data were presented in the form of numbers (No) and percentages (\%). Analytical statistics: Chi-square test $\left(\chi^{2}\right)$ was used to study relationship between two qualitative variables. Spearman correlation (r) test was used to measure the association between two qualitative variables. Significance was adopted at $\mathrm{p}<0.05$ for interpretation of results of 


\section{Relationship between Perceived Parenting styles and Depressive Symptoms among Selected University Students}

tests of significance. $\mathrm{P}$ value of $<0.001$ was considered statistically highly significant. $P$ value of $>0.05$ was considered statistically non-significant.

\section{RESULTS:}

Table 1 showed that majority of students $(80.3 \%)$ were females and the mean age was 19.6 \pm 0.74 . More than two thirds of the students $(68.0 \%)$ were from rural residence. More than one third of fathers (36.6\%) had higher education. More than one third of mothers $(40.4 \%)$ had secondary education. the majority of the fathers $(89.9 \%)$ were employee while more than half $(68.1 \%)$ of the mothers were housewives.

Table 2 showed that there was a negative significance correlation coefficient between authoritative parenting style and depressive symptoms while there was a positive correlation coefficient between authoritarian parenting style and depressive symptoms. Figure 1 revealed that the most common parenting styles used was moderate authoritative style $(36,10 \%)$ for father and $(38 \%)$ for mother.

Figure 2 revealed that more than half of the students $(53 \%)$ had mild depressive symptoms while only (17.80\%) had severe symptoms.

Table (1): Social characteristics of studied sample $(\mathrm{N}=527)$ :

\begin{tabular}{|c|c|c|}
\hline Social Characteristics & No. & $\%$ \\
\hline $\begin{array}{l}\text { Age / years }(\overline{\mathrm{X}} \pm \mathrm{SD}) \\
\text { Range }\end{array}$ & \multicolumn{2}{|c|}{$\begin{array}{c}19.6 \pm 0.74 \\
18-22\end{array}$} \\
\hline $\begin{array}{cl}\text { Gender } & \\
- & \text { Male } \\
- & \text { Female }\end{array}$ & $\begin{array}{l}104 \\
423\end{array}$ & $\begin{array}{l}19.7 \\
80.3\end{array}$ \\
\hline $\begin{array}{cc}\text { Residence: } \\
-\quad \text { Urban } \\
-\quad \text { Rural }\end{array}$ & $\begin{array}{l}166 \\
361\end{array}$ & $\begin{array}{l}31.0 \\
68.0\end{array}$ \\
\hline $\begin{aligned} & \text { Father education : } \\
&- \text { Illiterate } \\
&- \text { Read and write } \\
&- \text { Basic education } \\
&- \text { Secondary education } \\
&- \text { University }\end{aligned}$ & $\begin{array}{c}25 \\
35 \\
89 \\
185 \\
193\end{array}$ & $\begin{array}{c}4.7 \\
6.6 \\
16.9 \\
35.1 \\
36.6\end{array}$ \\
\hline $\begin{array}{cl}\text { Mother education : } \\
- & \text { Illiterate } \\
- & \text { Read and write } \\
- & \text { Basic education } \\
- & \text { Secondary education } \\
- & \text { University }\end{array}$ & $\begin{array}{c}72 \\
48 \\
71 \\
213 \\
123\end{array}$ & $\begin{array}{c}13.7 \\
9.1 \\
13.5 \\
40.4 \\
23.3\end{array}$ \\
\hline $\begin{aligned} \text { Father job: } \\
-\quad \text { Working } \\
-\quad \text { Not working }\end{aligned}$ & $\begin{array}{c}474 \\
52\end{array}$ & $\begin{array}{l}89.9 \\
10.1\end{array}$ \\
\hline $\begin{aligned} \text { Mother job: } & \\
- & \text { Working } \\
- & \text { Not working }\end{aligned}$ & $\begin{array}{l}168 \\
359\end{array}$ & $\begin{array}{l}31.9 \\
68.1\end{array}$ \\
\hline
\end{tabular}


Relationship between Perceived Parenting styles and Depressive Symptoms among Selected University Students

Table (2): Correlation between mean score of depressive symptoms and different parenting styles.

\begin{tabular}{||l|c|c|}
\hline \multirow{2}{*}{ Parenting styles } & \multicolumn{2}{|c|}{ Depressive symptoms } \\
\cline { 2 - 3 } & $\mathbf{R}$ & $\mathbf{\%}$ \\
\hline Authoritative style & -0.355 & $\mathbf{0 . 0 0 1} * *$ \\
\hline Authoritarian style & 0.332 & $\mathbf{0 . 0 0 1 * *}$ \\
\hline Permissive style & 0.030 & 0.496 \\
\hline
\end{tabular}

Figure (1): Parenting styles of fathers and mothers of studied sample.

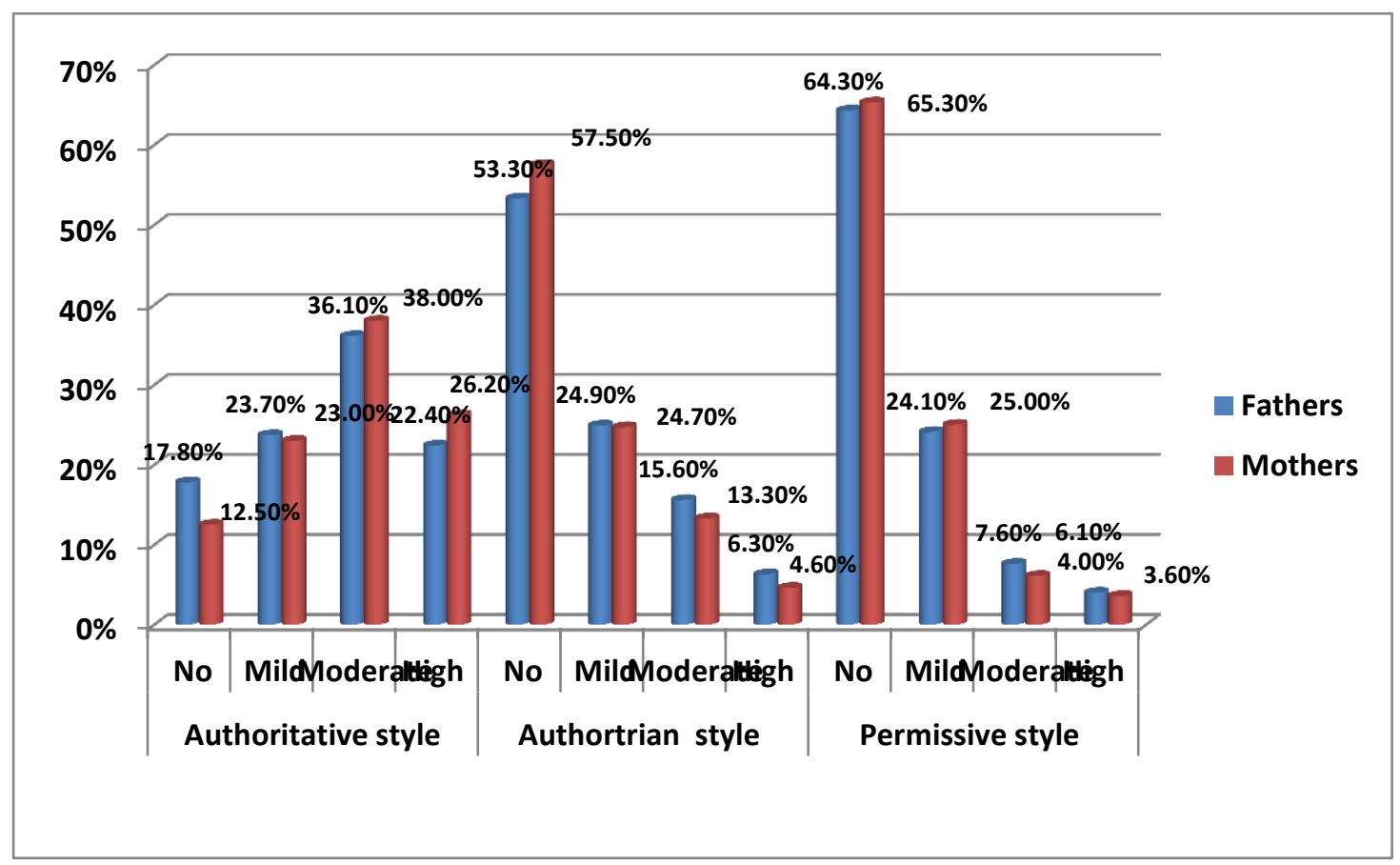

Figure (2): Level of depressive symptoms among studied sample

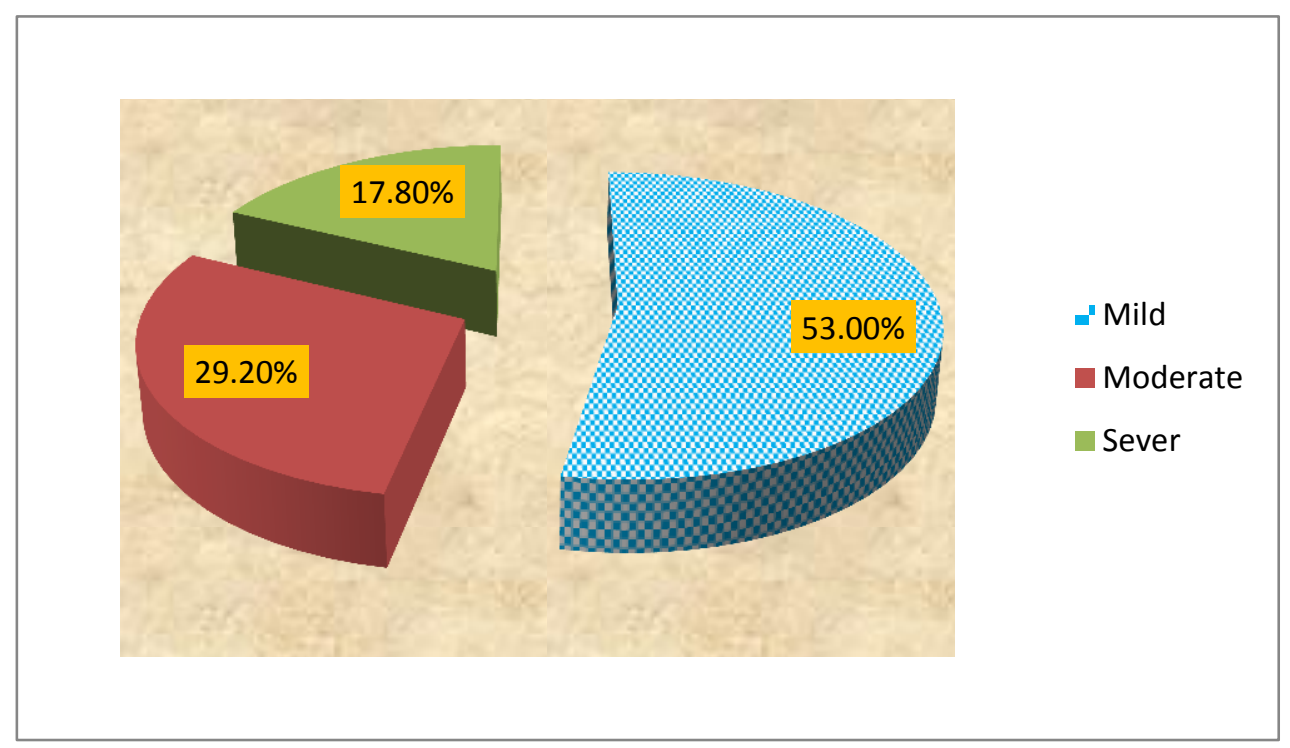




\section{Relationship between Perceived Parenting styles and Depressive Symptoms among Selected University Students}

\section{DISCUSSION}

Perceived parenting styles are opinions of adolescence about styles of parental behaviors during their childhood, assessment of parental behaviors is important. Parenting styles had crucial impacts on the psychological development of the adolescents and their future. This study raised two questions, first question was: What were the perceived parenting style among college students?

The current study revealed that the most common parenting style used by fathers and mothers was moderate authoritative style. This might be due to the effect of educational level of parents that helped them to deal correctly with their children .More than two thirds of mothers and approximately three quarter of fathers had secondary school or university education. This result was consistent with the study done by Chiew (2011) who studied the relationship between parenting styles and self- esteem of students. It was found that authoritative was the most practiced parenting style by parents of undergraduates' students in University Tunku Abdul Rahman. It was also consistent with a study done by Mintesinot (2014) who studied The Relationship of Parenting Style with Depression among Adolescent Patients of a Manuel Mental Specialized Hospital .He reported that authoritative parenting showed a higher proportion and exceeded the authoritarian parenting style to some extent. This result was in contrast with Smitha and Moore (2013) who studied Parenting style and psychosocial outcomes in a sample of Jamaican adolescent's .they reported that authoritarian is the most practiced parenting style.

The present study showed that more than half of the studied sample had mild depressive symptoms. This might be due to University students are a special group of people that are enduring a critical transitory period and can be one of the most stressful times in a person's life a reaction to this stress some students get depressed and attributed to parenting style. This result consistent with the study done by Abdallah and Gabr (2014) who studied Depression, anxiety and stress among first year medical students in an Egyptian public university .He found that nearly two thirds of students had depression among 1st year medical students at Menoufiya University. Also was consistent with Elmalky,Othman,Eita and Eldemerdash(2015)who studied The Effect of Birth Order and Socio Demographic Characteristics on Anxiety and Depression among Adolescents .They found that slightly more than half of the students had mild depression. This result was in contrast with Abdel Wahed and Hassan (2016) who studied Prevalence and associated factors of stress, anxiety and depression among medical Fayoum University students .They reported that more than one third of student had mild to moderate depression.

Second question: Is there a relationship between the perceived parenting styles and depressive symptoms?

The current study showed that there was a negative significante correlation between authoritative parenting style and depressive symptoms. This clarified that parental warmth and support of adolescence increased their skills to adjust their behavior, provided higher adaptation for their environment, increased their motivation and decreased their emotional problems. This study was consistent with astudy which done by Laboviti (2015) who studied Perceived Parenting Styles and their Impact on Depressive Symptoms in Adolescent 15-18 Years 


\section{Relationship between Perceived Parenting styles and Depressive Symptoms among Selected University Students}

Old .He reported that more perceived authoritative parent, as mother and father, less depressive symptoms among adolescents.

The current study showed that there was positive correlation coefficient between authoritarian parent style and depressive symptoms. This might be due to over control, decreased warmth and support from parents. This study was consistent with astudy which done by Hearne (2015) who studied The Effect of Parenting Styles and Depressive Symptoms on Young Adult's Educational Attainment. He found that authoritarian parenting were positively associated with depressive symptoms compared to authoritative parenting.

\section{CONCLUSION}

It was concluded that the most common parenting style used was moderate authoritative style and there was positive relationship between authoritarian parenting style and depressive symptoms

\section{RECOMMENDATIONS}

An educational program should be given for the parents of adolescents to increase their awareness about needs and problems of adolescents and how to satisfy their needs and adapt with their problems.

\section{REFERENCES}

Abdallah, A.R., \& Gabr, H.M. (2014). Depression, anxiety and stress among first year medical students in an Egyptian public university) International Research. Journal of Medicine and Medical Sciences, 2(1), 11-19.

Abdel Wahed, W.Y.,\& Hassan S.K.(2016). Prevalence and associated factors of stress, anxiety and depression among medical Fayoum University students, Alex J Med ,53,77-84 . http://dx.doi.org/10.1016/j.ajme.2 016.01 .005 .

American Foundation for Suicide Prevention. (2016). Interactive Screening Program. Retrieved from http://afsp.org/ourwork/interactive-screeningprogram/

Chiew, L.Y. (2011). A Study of Relationship between Parenting Styles and Self-esteem: Selfesteem's Indicator-Parenting Styles. Universiti Tunku Abdul Rahman.

Clark, S.W. (2015). Predicting Depression Symptoms Among College

Students: The Influence of Parenting Style) Virginia Common wealth University,Richmond, Virginia.

Elstad, J.I., \& Stefansen, K.(2014). Social Variations in Perceived Parenting Styles among Norwegian Adolescents. Child Ind Res, 7, 649-670. doi: 10. 1007/s 12187-014-9239-5.

Elmalky, M.I., Othman, Z.A., Eita, L.H., \& Eldemerdash, K.I. (2015). The Effect of Birth Order and Socio- Demographic Characteristics on Anxiety and Depression among Adolescents. International Journal of Nursing Science, 5(3), 110-121.doi: 0.5923/j. nursing. 20150503. 04.

Gogoi, H.S. (2016). A Cross Sectional Study of The Prevalence Of Depression Among The Male Post-Graduate Medical Students Of Gauhati Medical College And Hospital. European Scientific Journal, $12 \quad$ (14). doi:10.19044/esj.2016.v12n14p2 62

URL:http://dx.doi.org/10.19044/e sj.2016.v12n14p262.

Hearne,B.N.(2015). The Effect of Parenting Styles and Depressive 


\section{Relationship between Perceived Parenting styles and Depressive Symptoms among Selected University Students}

Symptoms on Young Adult's Educational Attainment.

Nashville, Tennessee.

Kumari, C., \& Khanna, A.(2016). Parenting styles and moral judgment among Adolescents. International Journal of Applied Research, 2(2), 572-574.

Laboviti,B.(2015). Perceived Parenting Styles and their Impact on Depressive Symptoms in Adolescent 15-18 Years Old. Journal of Educational and Social Research, 5(1). doi: 10.5901/ jesr. 2015. V5n1p171.

Lasic, D., Uglesic, B., ZuljanCvitanoviC, M., BukoviC, D., KareloviC, D., DeliC-BrkljaCiC, D., Radan, M. (2014). Prevalence of Depressive Symptoms among College Students and the Influence of Sport Activity. Coll. Antropol,38 (1), 235-239.

Iovu, M. (2014). Adolescents' Positive Expectations and Future Worries on their Transition to Adult
hood.Procedia - Social and Behavioral Sciences, 149 , 433 437.

Mintesinot, M. (2014). The Relationship of Parenting Style and Socioeconomic Status with Depression among Adolescent Patients of amanuel Mental Specialized Hospital. Addis Ababa University

Smith, D.E., \& Moore, T. M. (2013). Parenting style and psychosocial outcomes in a sample of Jamaican adolescents, International Journal of Adolescence and Youth, 18(3), 176-190.doi: 10.1080/02673843.2012.682593.

Yu, Y., Yang, X., Yang, Y., Chen, L., Qiu, X., Qiao,Z.,...,Bai,B .(2015) .The Role of Family Environment in Depressive Symptoms among University Students: ALarge Sample Survey in China. PLoS ONE 10 (12). doi: 10.1371/ journal. pone. 0143612 . 